\title{
Synthesis, characterization and evaluation of biological activities of some 2,3-diaryl bicyclo methanones
}

\author{
Ganesamoorthy THIRUNARAYANAN*
}

Department of Chemistry, Annamalai University, Annamalainagar 608 002, India

\begin{abstract}
Sixteen (3,4-dichlorophenyl)-3-(substituted phenyl)bicyclo[2.2.1]hept-5-ene-2-yl) methanone derivatives have been synthesized by an aqueous phase fly-ash catalyzed [4+2] cycloaddition Diels-Alder reaction of cyclopentadiene and 3,4-dichloro phenyl chalcones. The yields of the methanones were greater than $60 \%$. The synthesized methanones were characterized by their physical constants and spectral data. The antimicrobial and antioxidant activities of the synthesized methanones were evaluated using a variety of bacterial and fungal species and DPPH radical scavenging methods.
\end{abstract}

Keywords: bicyclo[2.2.1]hept-5-ene-2-yl-methanones; Diels-Alder reaction; antimicrobial activities; antioxidant activity.

\section{Introduction}

Methanones are versatile key intermediates [1] and important bioactive molecules [2, 3] due to carbonyl tautomer's, presence of polar groups and the degree of hydrophilicity or hydrophobicity. Methyl ketones and bicyclo methanones possess many pharmacological activities such as, AVP release and activation of vasopressin receptors [3], antimicrobial [4-15], cannabinoid receptor agonists [16], neuronal nicotinic acetylcholine receptors (nAChRs) [17], anti-inflammatory [12, 13, 18, 19], analgesic [10, 19], anticonvulsant [10, 19], antitumor [19], anticancer [10], antiviral [19], anti-diabetic [10, 20], antitubercular [20], antihelminthic [12, 20], antidepressant [21], ulcerogenic [18], antinociceptive [10], protein tyrosine kinase inhibitor [22], DNA cleavage [23], Alzheimer's disease curing agent [24], antioxidant [25], acute toxicity [18], antihypertensive [10] and insect antifeedant activities [25]. Numerous solvent-free and solvent assisted synthetic methods with or without catalysts were reported in the literature for the synthesis of stereo selective monoand bicyclo- methanones [26-28]. Aqueous phase Diels-Alder reaction is one of the best reactions for the synthesis of bicyclo methanones. This reaction involves [4+2] cycloaddition of diene and dienophiles. Rideout and Breslow [29] have studied the aqueous phase reaction of cyclopentadiene and vinyl methyl ketones in water. Many catalysts including Lewis acids [29], Brönsted acids [29, 30], asymmetric catalysts with helical polymers [31], $\mathrm{Cu}^{2+}$ ion-mediated nanotubes [32], DNA and micellarbased catalysts [33-37], have been employed for this
[4+2] cycloaddition Diels-Alder reaction of cyclopentadiene (diene) and $E$-chalcones (dienophiles). Recently, Thirunarayanan has reported the synthesis and antimicrobial, antioxidant and insect antifeedant activities of some 2-naphthyl based bicyclo methanones [25]. The synthesis of 3,4dichlorophenyl based-heptane[2.2.1]methanones by aqueous phase fly-ash catalyzed Diels-Alder reaction of cyclopentadiene and 3,4-dichlorophenyl chalcones has not been reported. Hence, the author have synthesize some 2-(3,4-dichlorophenyl)-3(substituted phenyl)heptene[2.2.1]methanones and evaluated their antimicrobial and antioxidant activities using the appropriate microbial strains with Bauer-Kirby [38] and DPPH radical scavenging [39] methods.

\section{Experimental}

\subsection{General}

All chemicals were procured from Sigma-Aldrich and E. Merck. Fly-ash was collected from the Thermal Power Plant-II, Neyveli Lignite Corporation (NLC), Neyveli, Tamil Nadu, India. Melting points of substituted aryl bicyclo[2.2.1]heptene-2-ylmethanones were determined in open glass capillaries on a Mettler FP51 melting point apparatus and are uncorrected. Infrared spectra $\left(\mathrm{KBr}, 4000-400 \mathrm{~cm}^{-1}\right)$ were recorded on Thermo Scientific Nicolet iS5, USmade Fourier transform spectrophotometer. The NMR spectra of selective compounds were recorded on a Bruker AV 400 spectrometer operating at 400 $\mathrm{MHz}$ for ${ }^{1} \mathrm{H} \mathrm{NMR}$ spectra and $100 \mathrm{MHz}$ for ${ }^{13} \mathrm{C} \mathrm{NMR}$ spectra in $\mathrm{CDCl}_{3}$ solvent using TMS as internal standard. Electron impact and chemical ionization

\footnotetext{
*E-mail: thirunarayanan.g.10313@annamalaiuniversity.ac.in; drgtnarayanan@gmail.com
} 
mode $\mathrm{FAB}^{+}$mass spectra were recorded with a Shimadzu spectrometer. The elemental analysis of all methanones were performed in a Perkin Elmer 240C analyzer.

\subsection{Synthesis of 2-naphthyl chalcones}

The substituted styryl 3,4-dichlorophenyl ketones were synthesized as described in reference [40].
2.3. General procedure for synthesis of 3,4dichlorophenyl bicyclo[2.2.1]heptene-2-ylmethanones

Appropriate equimolar quantities of 3,4dichlorophenyl chalcones $(2 \mathrm{mmol})$ in $15 \mathrm{~mL}$ of ethanol, cyclopentadiene ( $2 \mathrm{mmol})$ and $1 \mathrm{~g}$ of fly-ash in $20 \mathrm{~mL}$ of water were stirred for $6 \mathrm{~h}$ at $0-4^{\circ} \mathrm{C}$ overnight (Scheme 1).
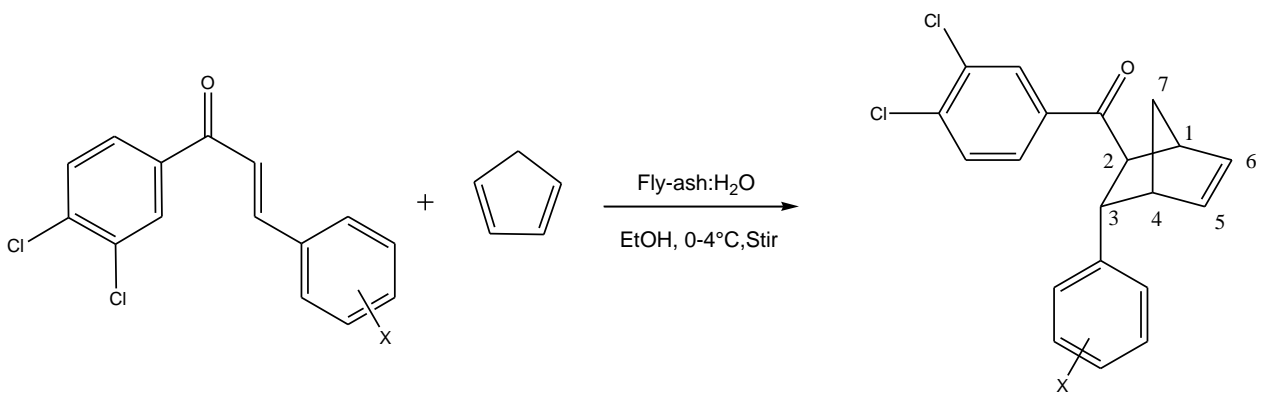

$\mathrm{X}=\mathrm{H}$, 3-NH$, 3-\mathrm{Br}, 2-\mathrm{Cl}, 3-\mathrm{Cl}, 4-\mathrm{Cl}, 4-\mathrm{N}\left(\mathrm{CH}_{3}\right)_{2}, 4-\mathrm{F}, 2-\mathrm{OH}, 4-\mathrm{OH}, 3-\mathrm{OCH}_{3}, 4-\mathrm{OCH}_{3}, 4-\mathrm{CH}_{3}, 2-\mathrm{NO}_{2}, 3-\mathrm{NO}_{2}, 4-\mathrm{NO}_{2}$

Scheme 1. Synthesis of (3-substituted phenyl)bicyclo[2.2.1]hept-5-en-2-yl)-3-(3,4-dichlorophenyl) methanone derivatives by fly-ash catalyzed aqueous phase Diels-Alder [4+2] cycloaddition of 3,4-dichlorophenyl chalcones and cyclopentadiene.

Progress of the reaction was monitored by thinlayer chromatography. Dichloromethane $(10 \mathrm{~mL})$ was added and the extract was separated by filtration. The filtrate was washed with water, brine $(10 \mathrm{~mL})$, dried over anhydrous $\mathrm{Na}_{2} \mathrm{SO}_{4}$ and concentrated to give a solid product. The crude product was further purified by recrystallization with ethanol.

Infrared and NMR spectral data of methanones are as follows.

(3,4-Dichlorophenyl)(3-phenylbicyclo[2.2.1]hept-5en-2-yl)methanone (Compound 1): IR $\left(\mathrm{KBr}, \mathrm{cm}^{-1}\right): v$ $=3028,2913,1665,1463,838,723 ;{ }^{1} \mathrm{H}$ NMR $(400$ $\left.\mathrm{MHz}, \mathrm{CDCl}_{3}, 25^{\circ} \mathrm{C}, \mathrm{TMS}\right): \delta=3.691\left(\mathrm{dd}, 1 \mathrm{H}, \mathrm{H}_{1}\right.$, $J=6$ and $4 \mathrm{~Hz}$ ), 3.481 (t, $\left.1 \mathrm{H}, \mathrm{H}_{2}, J=19 \mathrm{~Hz}\right), 3.367$ (t, $\left.1 \mathrm{H}, \mathrm{H}_{3}, J=16 \mathrm{~Hz}\right), 2.667\left(\mathrm{dd}, 1 \mathrm{H}, \mathrm{H}_{4}, J=4.6\right.$ and $4 \mathrm{~Hz}), 6.251\left(\mathrm{~d}, 1 \mathrm{H}, \mathrm{H}_{5}, J=15 \mathrm{~Hz}\right), 6.424\left(\mathrm{~d}, 1 \mathrm{H}, \mathrm{H}_{6}\right.$, $J=15 \mathrm{~Hz}), 1.792\left(\mathrm{dd}, 1 \mathrm{H}, \mathrm{H}_{7}, J=4\right.$ and $\left.6 \mathrm{~Hz}\right), 1.631$ (dd, $1 \mathrm{H}, \mathrm{H}_{7^{\prime}}, J=8$ and $\left.6 \mathrm{~Hz}\right), 7.261-8.237$ (m, 8H, Ar$\mathrm{H}) ;{ }^{13} \mathrm{C} \mathrm{NMR}\left(100 \mathrm{MHz}, \mathrm{CDCl}_{3}, 25{ }^{\circ} \mathrm{C}, \mathrm{TMS}\right): \delta=$ $198.25(\mathrm{CO}), 46.68\left(\mathrm{C}_{1}\right), 52.74\left(\mathrm{C}_{2}\right), 44.68\left(\mathrm{C}_{3}\right), 46.68$ $\left(\mathrm{C}_{4}\right), 134.28\left(\mathrm{C}_{5}\right), 136.12\left(\mathrm{C}_{6}\right), 46.27\left(\mathrm{C}_{7}\right), 125.87-$ 147.28 (Ar-C);

(3-(3-Aminophenyl)bicyclo[2.2.1]hept-5-en-2-

yl)(3,4-dichlorophenyl)methanone (Compound 2): IR $\left(\mathrm{KBr}, \mathrm{cm}^{-1}\right): v=3456,2814,1668,1462,1298,864$, 715; ${ }^{1} \mathrm{H}$ NMR(400MHz, $\mathrm{CDCl}_{3}, 25{ }^{\circ} \mathrm{C}$, TMS $): \delta=$ $3.692\left(\mathrm{dd}, 1 \mathrm{H}, \mathrm{H}_{1}, J=4\right.$ and $\left.4.8 \mathrm{~Hz}\right), 3.471(\mathrm{t}, 1 \mathrm{H}$, $\mathrm{H}_{2}, J=18 \mathrm{~Hz}$ ), 3.313 (t, 1H, $\left.\mathrm{H}_{3}, J=17 \mathrm{~Hz}\right), 2.728$ $\left(\mathrm{dd}, 1 \mathrm{H}, \mathrm{H}_{4}, J=6\right.$ and $\left.4 \mathrm{~Hz}\right), 6.115\left(\mathrm{~d}, 1 \mathrm{H}, \mathrm{H}_{5}, J=16\right.$ $\mathrm{Hz}), 6.835\left(\mathrm{~d}, 1 \mathrm{H}, \mathrm{H}_{6}, J=16 \mathrm{~Hz}\right), 1.802\left(\mathrm{dd}, 1 \mathrm{H}, \mathrm{H}_{7}\right.$, $J=6.4$ and $4 \mathrm{~Hz}), 1.624\left(\mathrm{dd}, 1 \mathrm{H}, \mathrm{H}_{7^{\prime}}, J=4.8\right.$ and $\left.6 \mathrm{~Hz}\right)$, 6.643 (s, 2H, NH$), 6.452-8.312(\mathrm{~m}, 7 \mathrm{H}, \mathrm{Ar}-\mathrm{H}) ;{ }^{13} \mathrm{C}$ NMR (100 MHz, $\left.\mathrm{CDCl}_{3}, 25^{\circ} \mathrm{C}, \mathrm{TMS}\right): \delta=197.66$
(CO), $46.73\left(\mathrm{C}_{1}\right), 52.76\left(\mathrm{C}_{2}\right), 44.84\left(\mathrm{C}_{3}\right), 46.48\left(\mathrm{C}_{4}\right)$, $134.26\left(\mathrm{C}_{5}\right), 135.92\left(\mathrm{C}_{6}\right), 46.37\left(\mathrm{C}_{7}\right), 112.73-146.92$ (Ar-C).

(3-(3-Bromophenyl)bicyclo[2.2.1]hept-5-en-2yl)(3,4-dichlorophenyl)methanone (Compound 3): IR $\left(\mathrm{KBr}, \mathrm{cm}^{-1}\right): v=3061,2925,1671,1425,1236,1065$, 892, 751, 623; ${ }^{1} \mathrm{H}$ NMR (400 MHz, $\mathrm{CDCl}_{3}, 25{ }^{\circ} \mathrm{C}$, TMS $): \delta=3.711\left(\mathrm{dd}, 1 \mathrm{H}, \mathrm{H}_{1}, J=6\right.$ and $\left.4.8 \mathrm{~Hz}\right), 3.481$ (t, $\left.1 \mathrm{H}, \mathrm{H}_{2}, J=16 \mathrm{~Hz}\right), 3.363\left(\mathrm{t}, 1 \mathrm{H}, \mathrm{H}_{3}, J=14.5 \mathrm{~Hz}\right.$ ), $2.713\left(\mathrm{dd}, 1 \mathrm{H}, \mathrm{H}_{4}, J=6.8\right.$ and $\left.4 \mathrm{~Hz}\right), 6.217\left(\mathrm{~d}, 1 \mathrm{H}, \mathrm{H}_{5}\right.$, $J=15.5 \mathrm{~Hz}), 6.301\left(\mathrm{~d}, 1 \mathrm{H}, \mathrm{H}_{6}, J=15.5 \mathrm{~Hz}\right), 1.791$ $\left(\mathrm{dd}, 1 \mathrm{H}, \mathrm{H}_{7}, J=4.8\right.$ and $\left.4 \mathrm{~Hz}\right), 1.641\left(\mathrm{dd}, 1 \mathrm{H}, \mathrm{H}_{7^{\prime}}, J=\right.$ 8 and $6 \mathrm{~Hz}), 7.263-8.317(\mathrm{~m}, 7 \mathrm{H}, \mathrm{Ar}-\mathrm{H}) ;{ }^{13} \mathrm{CNMR}(100$ $\left.\mathrm{MHz}, \mathrm{CDCl}_{3}, 25^{\circ} \mathrm{C}, \mathrm{TMS}\right): \delta=194.25(\mathrm{CO}), 46.67\left(\mathrm{C}_{1}\right)$, $52.83\left(\mathrm{C}_{2}\right), 44.71\left(\mathrm{C}_{3}\right), 46.53\left(\mathrm{C}_{4}\right), 135.22\left(\mathrm{C}_{5}\right)$, $136.04\left(\mathrm{C}_{6}\right), 46.39\left(\mathrm{C}_{7}\right), 122.71-148.25$ (Ar-C).

(3-(2-Chlorophenyl)bicyclo[2.2.1]hept-5-en-2yl)(3,4-dichlorophenyl)methanone (Compound 4): IR $\left(\mathrm{KBr}, \mathrm{cm}^{-1}\right): v=3026,1647,1563,1358,1245,1064$, 932, 810, 723; ${ }^{1} \mathrm{H}$ NMR (400 MHz, $\mathrm{CDCl}_{3}, 25{ }^{\circ} \mathrm{C}$, TMS): $\delta=3.721\left(\mathrm{dd}, 1 \mathrm{H}, \mathrm{H}_{1}, J=6\right.$ and $\left.8 \mathrm{~Hz}\right), 3.507$ $\left(\mathrm{t}, 1 \mathrm{H}, \mathrm{H}_{2}, J=19 \mathrm{~Hz}\right), 3.473\left(\mathrm{t}, 1 \mathrm{H}, \mathrm{H}_{3}, J=18 \mathrm{~Hz}\right.$ ), $2.695\left(\mathrm{dd}, 1 \mathrm{H}, \mathrm{H}_{4}, J=6.4\right.$ and $\left.4 \mathrm{~Hz}\right), 6.217(\mathrm{~d}, 1 \mathrm{H}$, $\left.\mathrm{H}_{5}, J=18 \mathrm{~Hz}\right), 6.831\left(\mathrm{~d}, 1 \mathrm{H}, \mathrm{H}_{6}, J=18 \mathrm{~Hz}\right), 1.781$ (dd, $1 \mathrm{H}, \mathrm{H}_{7}, J=5.6$ and $\left.6.4 \mathrm{~Hz}\right), 1.645\left(\mathrm{dd}, 1 \mathrm{H}, \mathrm{H}_{7^{\prime}}, J=\right.$ 8 and $6.4 \mathrm{~Hz}), 7.217-8.349$ (m, 7H, Ar-H); ${ }^{13} \mathrm{C} \mathrm{NMR}$ (100 MHz, $\left.\mathrm{CDCl}_{3}, 25^{\circ} \mathrm{C}, \mathrm{TMS}\right): \delta=190.53$ (CO), 46.72 $\left(\mathrm{C}_{1}\right), 52.71\left(\mathrm{C}_{2}\right), 44.69\left(\mathrm{C}_{3}\right), 46.51\left(\mathrm{C}_{4}\right), 135.72\left(\mathrm{C}_{5}\right)$, $136.14\left(\mathrm{C}_{6}\right), 46.28\left(\mathrm{C}_{7}\right), 126.41-143.72(\mathrm{Ar}-\mathrm{C})$.

(3-(3-Chlorophenyl)bicyclo[2.2.1]hept-5-en-2yl)(3,4-dichlorophenyl)methanone (Compound 5): IR $\left(\mathrm{KBr}, \mathrm{cm}^{-1}\right): v=3041,1658,1541,1354,1284,1058$, 
959, 858, 784; ${ }^{1} \mathrm{H}$ NMR (400 $\mathrm{MHz}, \mathrm{CDCl}_{3}, 25{ }^{\circ} \mathrm{C}$, TMS): $\delta=3.741\left(\mathrm{dd}, 1 \mathrm{H}, \mathrm{H}_{1}, J=8\right.$ and $\left.4 \mathrm{~Hz}\right), 3.517$ (t, $\left.1 \mathrm{H}, \mathrm{H}_{2}, J=16 \mathrm{~Hz}\right), 3.423\left(\mathrm{t}, 1 \mathrm{H}, \mathrm{H}_{3}, J=17 \mathrm{~Hz}\right)$, $2.699\left(\mathrm{dd}, 1 \mathrm{H}, \mathrm{H}_{4}, J=6\right.$ and $\left.8 \mathrm{~Hz}\right), 6.301\left(\mathrm{~d}, 1 \mathrm{H}, \mathrm{H}_{5}\right.$, $J=15 \mathrm{~Hz}), 6.714\left(\mathrm{~d}, 1 \mathrm{H}, \mathrm{H}_{6}, J=15 \mathrm{~Hz}\right), 1.794(\mathrm{dd}$, $1 \mathrm{H}, \mathrm{H}_{7}, J=6.4$ and $\left.4 \mathrm{~Hz}\right), 1.647\left(\mathrm{dd}, 1 \mathrm{H}, \mathrm{H}_{7^{\prime}}, J=5.6\right.$ and 6.4 Hz), 7.817-8.371 (m, 7H, Ar-H); ${ }^{13} \mathrm{CNMR}(100$ $\mathrm{MHz}, \mathrm{CDCl}_{3}, 25{ }^{\circ} \mathrm{C}$, TMS): $\delta=196.28$ (CO), 46.68 $\left(\mathrm{C}_{1}\right), 52.74\left(\mathrm{C}_{2}\right), 44.89\left(\mathrm{C}_{3}\right), 46.54\left(\mathrm{C}_{4}\right), 135.64\left(\mathrm{C}_{5}\right)$, $136.27\left(\mathrm{C}_{6}\right), 46.23\left(\mathrm{C}_{7}\right), 125.19-149.37$ (Ar-C).

(3-(4-Chlorophenyl)bicyclo[2.2.1]hept-5-en-2yl)(3,4-dichlorophenyl)methanone (Compound 6): IR $\left(\mathrm{KBr}, \mathrm{cm}^{-1}\right): v=3038,1678,1554,1362,1228,1081$, 962, 848, 735; ${ }^{1} \mathrm{H}$ NMR $\left(400 \mathrm{MHz}, \mathrm{CDCl}_{3}, 25{ }^{\circ} \mathrm{C}\right.$, TMS): $\delta=3.729\left(\mathrm{dd}, 1 \mathrm{H}, \mathrm{H}_{1}, J=6.4\right.$ and $4.8 \mathrm{~Hz}$ ), $3.621\left(\mathrm{t}, 1 \mathrm{H}, \mathrm{H}_{2}, J=19 \mathrm{~Hz}\right), 3.481\left(\mathrm{t}, 1 \mathrm{H}, \mathrm{H}_{3}, J=19\right.$ $\mathrm{Hz}), 2.690$ (dd, 1H, $\mathrm{H}_{4}, J=4$ and $\left.6.4 \mathrm{~Hz}\right), 6.314$ (d, $\left.1 \mathrm{H}, \mathrm{H}_{5}, J=15.5 \mathrm{~Hz}\right), 6.617$ (d, $1 \mathrm{H}, \mathrm{H}_{6}, J=15.5 \mathrm{~Hz}$ ), $1.751\left(\mathrm{dd}, 1 \mathrm{H}, \mathrm{H}_{7}, J=8\right.$ and $\left.6 \mathrm{~Hz}\right), 1.641\left(\mathrm{dd}, 1 \mathrm{H}, \mathrm{H}_{7^{\prime}}\right.$, $J=6$ and $4 \mathrm{~Hz}$ ), 7.245-8.217 (m, 7H, Ar-H); ${ }^{13} \mathrm{C}$ NMR (100 MHz, $\left.\mathrm{CDCl}_{3}, 25^{\circ} \mathrm{C}, \mathrm{TMS}\right): \delta=198.62(\mathrm{CO}), 46.62$ $\left(\mathrm{C}_{1}\right), 52.69\left(\mathrm{C}_{2}\right), 44.72\left(\mathrm{C}_{3}\right), 46.53\left(\mathrm{C}_{4}\right), 135.72\left(\mathrm{C}_{5}\right)$, $136.18\left(\mathrm{C}_{6}\right), 46.33\left(\mathrm{C}_{7}\right), 126.81-144.44$ (Ar-C).

(3-(4-Dimethylaminophenyl)bicyclo[2.2.1]hept-5en-2-yl)(3,4-dichlorophenyl)methanone (Compound 7): IR $\left(\mathrm{KBr}, \mathrm{cm}^{-1}\right): v=3321,2802,1664,1562,1368$, 1052, 813, 751; ${ }^{1} \mathrm{H}$ NMR (400 MHz, $\mathrm{CDCl}_{3}, 25^{\circ} \mathrm{C}$, TMS): $\delta=3.728$ (dd, $1 \mathrm{H}, \mathrm{H}_{1}, J=8$ and $\left.4 \mathrm{~Hz}\right), 3.611$ (t, $\left.1 \mathrm{H}, \mathrm{H}_{2}, J=19 \mathrm{~Hz}\right), 3.396$ (t, 1H, $\left.\mathrm{H}_{3}, J=17 \mathrm{~Hz}\right), 2.482$ $\left(\mathrm{dd}, 1 \mathrm{H}, \mathrm{H}_{4}, J=6\right.$ and $\left.4 \mathrm{~Hz}\right), 6.281\left(\mathrm{~d}, 1 \mathrm{H}, \mathrm{H}_{5}, J=18\right.$ $\mathrm{Hz}), 6.601$ (d, 1H, $\left.\mathrm{H}_{6}, J=18 \mathrm{~Hz}\right), 1.733$ (dd, 1H, $\mathrm{H}_{7}$, $J=4$ and $6 \mathrm{~Hz}), 1.655\left(\mathrm{dd}, 1 \mathrm{H}, \mathrm{H}_{7^{\prime}}, J=8\right.$ and $\left.6.4 \mathrm{~Hz}\right)$, $3.178\left(\mathrm{~s}, 6 \mathrm{H}, 2 \mathrm{CH}_{3}\right) ; 7.127-8.231(\mathrm{~m}, 7 \mathrm{H}, \mathrm{Ar}-\mathrm{H}) ;{ }^{13} \mathrm{C}$ NMR (100 MHz, $\left.\mathrm{CDCl}_{3}, 25{ }^{\circ} \mathrm{C}, \mathrm{TMS}\right): \delta=193.25$ (CO), $46.34\left(\mathrm{C}_{1}\right), 51.97\left(\mathrm{C}_{2}\right), 44.68\left(\mathrm{C}_{3}\right), 46.47\left(\mathrm{C}_{4}\right)$, $135.66\left(\mathrm{C}_{5}\right), 136.26\left(\mathrm{C}_{6}\right), 46.27\left(\mathrm{C}_{7}\right), 40.83\left(\mathrm{CH}_{3}\right)$, 112.67-148.80 (Ar-C).

(3-(4-Fluorophenyl)bicyclo[2.2.1]hept-5-en-2yl)(3,4-dichlorophenyl)methanone (Compound 8): IR $\left(\mathrm{KBr}, \mathrm{cm}^{-1}\right): v=3012,2799,1661,1526,1495,1387$, 1258, 1063, 952, 863, 729; ${ }^{1} \mathrm{H}$ NMR (400 MHz, $\mathrm{CDCl}_{3}, 25{ }^{\circ} \mathrm{C}$, TMS $): \delta=3.770\left(\mathrm{dd}, 1 \mathrm{H}, \mathrm{H}_{1}, J=6.4\right.$ and $8 \mathrm{~Hz}), 3.631\left(\mathrm{t}, 1 \mathrm{H}, \mathrm{H}_{2}, J=17 \mathrm{~Hz}\right), 3.394(\mathrm{t}, 1 \mathrm{H}$, $\left.\mathrm{H}_{3}, J=16 \mathrm{~Hz}\right), 2.695\left(\mathrm{dd}, 1 \mathrm{H}, \mathrm{H}_{4}, J=6\right.$ and $8 \mathrm{~Hz}$ ), $6.341\left(\mathrm{~d}, 1 \mathrm{H}, \mathrm{H}_{5}, J=19 \mathrm{~Hz}\right), 6.675\left(\mathrm{~d}, 1 \mathrm{H}, \mathrm{H}_{6}, J=\right.$ $19 \mathrm{~Hz}), 1.750\left(\mathrm{dd}, 1 \mathrm{H}, \mathrm{H}_{7}, J=4\right.$ and $\left.4.8 \mathrm{~Hz}\right), 1.639$ (dd, $1 \mathrm{H}, \mathrm{H}_{7^{\prime}}, J=7.6$ and $\left.5.6 \mathrm{~Hz}\right), 7.167-8.317(\mathrm{~m}, 7 \mathrm{H}$, Ar-H); ${ }^{13} \mathrm{C}$ NMR (100 MHz, $\mathrm{CDCl}_{3}, 25^{\circ} \mathrm{C}$, TMS $): \delta=$ $191.62(\mathrm{CO}), 47.71\left(\mathrm{C}_{1}\right), 52.81\left(\mathrm{C}_{2}\right), 44.81\left(\mathrm{C}_{3}\right)$, $46.78\left(\mathrm{C}_{4}\right), 135.73\left(\mathrm{C}_{5}\right), 136.18\left(\mathrm{C}_{6}\right), 46.57\left(\mathrm{C}_{7}\right)$, 115.71-142.85 (Ar-C).

(3-(2-Hydroxyphenyl)bicyclo[2.2.1]hept-5-en-2yl)(3,4-dichlorophenyl)methanone (Compound 9): IR $\left(\mathrm{KBr}, \mathrm{cm}^{-1}\right): v=3462,2841,1667,1535$, 1428, 1068, 958, 754; ${ }^{1} \mathrm{H}$ NMR (400 MHz, $\mathrm{CDCl}_{3}$, $25^{\circ} \mathrm{C}$, TMS): $\delta=3.776\left(\mathrm{dd}, 1 \mathrm{H}, \mathrm{H}_{1}, J=8\right.$ and $6.4 \mathrm{~Hz}$ ), $3.629\left(\mathrm{t}, 1 \mathrm{H}, \mathrm{H}_{2}, J=16 \mathrm{~Hz}\right), 3.381\left(\mathrm{t}, 1 \mathrm{H}, \mathrm{H}_{3}, J=19\right.$ $\mathrm{Hz}), 2.704\left(\mathrm{dd}, 1 \mathrm{H}, \mathrm{H}_{4}, J=4\right.$ and $\left.8 \mathrm{~Hz}\right), 6.352$ (d, $\left.1 \mathrm{H}, \mathrm{H}_{5}, J=16 \mathrm{~Hz}\right), 6.627$ (d, 1H, $\left.\mathrm{H}_{6}, J=16 \mathrm{~Hz}\right), 1.766$ $\left(\mathrm{dd}, 1 \mathrm{H}, \mathrm{H}_{7}, J=4.8\right.$ and $\left.6 \mathrm{~Hz}\right), 1.658\left(\mathrm{dd}, 1 \mathrm{H}, \mathrm{H}_{7^{\prime}}, J=\right.$ 8 and $4 \mathrm{~Hz}$ ), 5.621 (s, 1H, OH), 7.124-8.524 (m. 7H, $\mathrm{Ar}-\mathrm{H}) ;{ }^{13} \mathrm{C} \mathrm{NMR}\left(100 \mathrm{MHz}, \mathrm{CDCl}_{3}, 25^{\circ} \mathrm{C}, \mathrm{TMS}\right): \delta=$ $198.23(\mathrm{CO}), 47.24\left(\mathrm{C}_{1}\right), 52.37\left(\mathrm{C}_{2}\right), 44.62\left(\mathrm{C}_{3}\right), 46.83$ $\left(\mathrm{C}_{4}\right), 135.84\left(\mathrm{C}_{5}\right), 136.36\left(\mathrm{C}_{6}\right), 46.54\left(\mathrm{C}_{7}\right), 115.62-$ 137.38 (Ar-C).

(3-(4-Hydroxyphenyl)bicyclo[2.2.1]hept-5-en-2yl)(3,4-dichlorophenyl)methanone (Compound 10): IR $\left(\mathrm{KBr}, \mathrm{cm}^{-1}\right): v=3458,2871,1674,1562$, $1482,1028,935,781 ;{ }^{1} \mathrm{H} \mathrm{NMR}\left(400 \mathrm{MHz}, \mathrm{CDCl}_{3}\right.$, $25^{\circ} \mathrm{C}$, TMS $): \delta=3.769\left(\mathrm{dd}, 1 \mathrm{H}, \mathrm{H}_{1}, J=4\right.$ and $\left.6 \mathrm{~Hz}\right)$, $3.637\left(\mathrm{t}, 1 \mathrm{H}, \mathrm{H}_{2}, J=19 \mathrm{~Hz}\right), 3.271\left(\mathrm{t}, 1 \mathrm{H}, \mathrm{H}_{3}, J=17\right.$ $\mathrm{Hz}), 2.968\left(\mathrm{dd}, 1 \mathrm{H}, \mathrm{H}_{4}, J=8\right.$ and $\left.4 \mathrm{~Hz}\right), 6.314(\mathrm{~d}$, $\left.1 \mathrm{H}, \mathrm{H}_{5}, J=15 \mathrm{~Hz}\right), 6.651\left(\mathrm{~d}, 1 \mathrm{H}, \mathrm{H}_{6}, J=15 \mathrm{~Hz}\right), 1.756$ $\left(\mathrm{dd}, 1 \mathrm{H}, \mathrm{H}_{7}, J=6\right.$ and $\left.4 \mathrm{~Hz}\right), 1.640\left(\mathrm{dd}, 1 \mathrm{H}, \mathrm{H}_{7^{\prime}}, J=8\right.$ and $6 \mathrm{~Hz}), 5.371(\mathrm{~s}, 1 \mathrm{H}, \mathrm{OH}), 6.671-8.391(\mathrm{~m}, 7 \mathrm{H}$, $\mathrm{Ar}-\mathrm{H}) ;{ }^{13} \mathrm{C} \mathrm{NMR}\left(100 \mathrm{MHz}, \mathrm{CDCl}_{3}, 25^{\circ} \mathrm{C}, \mathrm{TMS}\right): \delta=$ $199.72(\mathrm{CO}), 47.34\left(\mathrm{C}_{1}\right), 52.74\left(\mathrm{C}_{2}\right), 44.56\left(\mathrm{C}_{3}\right), 46.67$ $\left(\mathrm{C}_{4}\right), 135.67\left(\mathrm{C}_{5}\right), 136.29\left(\mathrm{C}_{6}\right), 46.32\left(\mathrm{C}_{7}\right), 115.61-$ 138.73 (Ar-C).

(3-(3-Methoxyphenyl)bicyclo[2.2.1]hept-5-en-2yl)(3,4-dichlorophenyl)methanone (Compound 11): IR $\left(\mathrm{KBr}, \mathrm{cm}^{-1}\right): v=3065,2810,1628,1539,1424$, 1246, 1095, 962, 827, 739; ${ }^{1} \mathrm{H}$ NMR (400 MHz, $\mathrm{CDCl}_{3}, 25^{\circ} \mathrm{C}$, TMS): $\delta=3.721\left(\mathrm{dd}, 1 \mathrm{H}, \mathrm{H}_{1}, J=6\right.$ and $4 \mathrm{~Hz}$ ), 3.621 (t, 1H, $\mathrm{H}_{2}, J=18 \mathrm{~Hz}$ ), 3.267 (t, 1H, $\mathrm{H}_{3}, J$ $=17 \mathrm{~Hz}), 2.674\left(\mathrm{dd}, 1 \mathrm{H}, \mathrm{H}_{4}, J=4\right.$ and $\left.6 \mathrm{~Hz}\right), 6.431(\mathrm{~d}$, $\left.1 \mathrm{H}, \mathrm{H}_{5}, J=18 \mathrm{~Hz}\right), 6.649$ (d, 1H, $\left.\mathrm{H}_{6}, J=18 \mathrm{~Hz}\right), 1.775$ (dd, $1 \mathrm{H}, \mathrm{H}_{7}, J=8$ and $\left.6 \mathrm{~Hz}\right), 1.646\left(\mathrm{dd}, 1 \mathrm{H}, \mathrm{H}_{7^{\prime}}, J=4\right.$ and $6 \mathrm{~Hz}), 3.817\left(\mathrm{~s}, 3 \mathrm{H}, \mathrm{OCH}_{3}\right), 6.817-8.571(\mathrm{~m}, 7 \mathrm{H}$, $\mathrm{Ar}-\mathrm{H}) ;{ }^{13} \mathrm{C} \mathrm{NMR}\left(100 \mathrm{MHz}, \mathrm{CDCl}_{3}, 25^{\circ} \mathrm{C}, \mathrm{TMS}\right): \delta=$ $193.05(\mathrm{CO}), 47.54\left(\mathrm{C}_{1}\right), 53.76\left(\mathrm{C}_{2}\right), 44.92\left(\mathrm{C}_{3}\right)$, $46.83\left(\mathrm{C}_{4}\right), 135.74\left(\mathrm{C}_{5}\right), 136.34\left(\mathrm{C}_{6}\right), 46.59\left(\mathrm{C}_{7}\right)$, $59.73\left(\mathrm{OCH}_{3}\right), 114.47-145.78(\mathrm{Ar}-\mathrm{C})$.

(3-(4-Methoxyphenyl)bicyclo[2.2.1]hept-5-en-2yl)(3,4-dichlorophenyl)methanone (Compound 12): IR $\left(\mathrm{KBr}, \mathrm{cm}^{-1}\right): v=3071,2812,1623,1542,1436$, 1229, 1081, 968, 851, 746; ${ }^{1} \mathrm{H}$ NMR (400 MHz, $\mathrm{CDCl}_{3}, 25^{\circ} \mathrm{C}$, TMS): $\delta=3.743\left(\mathrm{dd}, 1 \mathrm{H}, \mathrm{H}_{1}, J=8\right.$ and $4 \mathrm{~Hz}$ ), 3.613 (t, 1H, $\mathrm{H}_{2}, J=16 \mathrm{~Hz}$ ), 3.224 (t, 1H, $\mathrm{H}_{3}, J$ $=17 \mathrm{~Hz}), 2.663\left(\mathrm{dd}, 1 \mathrm{H}, \mathrm{H}_{4}, J=4\right.$ and $\left.6 \mathrm{~Hz}\right), 6.441(\mathrm{~d}$, $\left.1 \mathrm{H}, \mathrm{H}_{5}, J=15 \mathrm{~Hz}\right), 6.637$ (d, 1H, $\left.\mathrm{H}_{6}, J=15 \mathrm{~Hz}\right), 1.747$ (dd, $1 \mathrm{H}, \mathrm{H}_{7}, J=6$ and $\left.4.8 \mathrm{~Hz}\right), 1.631\left(\mathrm{dd}, 1 \mathrm{H}, \mathrm{H}_{7^{\prime}}, J=4\right.$ and $6 \mathrm{~Hz}), 3.837\left(\mathrm{~s}, 3 \mathrm{H}, \mathrm{OCH}_{3}\right), 6.913-8.538(\mathrm{~m}, 7 \mathrm{H}$, $\mathrm{Ar}-\mathrm{H}) ;{ }^{13} \mathrm{C} \mathrm{NMR}\left(100 \mathrm{MHz}, \mathrm{CDCl}_{3}, 25^{\circ} \mathrm{C}, \mathrm{TMS}\right): \delta=$ $193.25(\mathrm{CO}), 47.59\left(\mathrm{C}_{1}\right), 53.87\left(\mathrm{C}_{2}\right), 44.83\left(\mathrm{C}_{3}\right)$, $46.72\left(\mathrm{C}_{4}\right), 135.66\left(\mathrm{C}_{5}\right), 136.22\left(\mathrm{C}_{6}\right), 46.34\left(\mathrm{C}_{7}\right)$, $62.78\left(\mathrm{OCH}_{3}\right), 113.92-139.75(\mathrm{Ar}-\mathrm{C})$.

(3-(4-Methylphenyl)bicyclo[2.2.1]hept-5-en-2yl)(3,4-dichlorophenyl)methanone (Compound 13): IR $\left(\mathrm{KBr}, \mathrm{cm}^{-1}\right): v=2994,2801,1654,1598,1423$, 
1459, 1062, 965, 824, 751; ${ }^{1} \mathrm{H}$ NMR $(400 \mathrm{MHz}$, $\mathrm{CDCl}_{3}, 25^{\circ} \mathrm{C}$, TMS): $\delta=3.747\left(\mathrm{dd}, 1 \mathrm{H}, \mathrm{H}_{1}, J=6\right.$ and $8 \mathrm{~Hz}$ ), 3.607 (t, 1H, $\left.\mathrm{H}_{2}, J=19 \mathrm{~Hz}\right), 3.217$ (t, $1 \mathrm{H}, \mathrm{H}_{3}, J$ $=16 \mathrm{~Hz}), 2.689\left(\mathrm{dd}, 1 \mathrm{H}, \mathrm{H}_{4}, J=8\right.$ and $\left.4 \mathrm{~Hz}\right), 6.437(\mathrm{~d}$, $\left.1 \mathrm{H}, \mathrm{H}_{5}, J=16 \mathrm{~Hz}\right), 6.651\left(\mathrm{~d}, 1 \mathrm{H}, \mathrm{H}_{6}, J=16 \mathrm{~Hz}\right), 1.748$ $\left(\mathrm{dd}, 1 \mathrm{H}, \mathrm{H}_{7}, J=4\right.$ and $\left.8 \mathrm{~Hz}\right), 1.639\left(\mathrm{dd}, 1 \mathrm{H}, \mathrm{H}_{7^{\prime}}, J=6\right.$ and $8 \mathrm{~Hz}), 2.37\left(\mathrm{~s}, 3 \mathrm{H}, \mathrm{CH}_{3}\right), 7.158-8.536(\mathrm{~m}, 7 \mathrm{H}, \mathrm{Ar}-$ $\mathrm{H}) ;{ }^{13} \mathrm{C}$ NMR $\left(100 \mathrm{MHz}, \mathrm{CDCl}_{3}, 25{ }^{\circ} \mathrm{C}\right.$, TMS $): \delta=$ $195.24(\mathrm{CO}), 47.61\left(\mathrm{C}_{1}\right), 53.97\left(\mathrm{C}_{2}\right), 44.92\left(\mathrm{C}_{3}\right)$, $46.69\left(\mathrm{C}_{4}\right), 135.72\left(\mathrm{C}_{5}\right), 136.34\left(\mathrm{C}_{6}\right), 46.28\left(\mathrm{C}_{7}\right)$, $24.72\left(\mathrm{CH}_{3}\right), 126.38-143.81$ (Ar-C).

(3-(2-Nitrophenyl)bicyclo[2.2.1]hept-5-en-2-yl)(3,4dichlorophenyl)methanone (Compound 14): IR ( $\mathrm{KBr}$, $\left.\mathrm{cm}^{-1}\right): v=3123,2954,1674,1532,1428,1047,946$, 825, 792; ${ }^{1} \mathrm{H}$ NMR (400 MHz, $\left.\mathrm{CDCl}_{3}, 25{ }^{\circ} \mathrm{C}, \mathrm{TMS}\right)$ : $\delta=3.767\left(\mathrm{dd}, 1 \mathrm{H}, \mathrm{H}_{1}, J=6\right.$ and $\left.8 \mathrm{~Hz}\right), 3.617(\mathrm{t}, 1 \mathrm{H}$, $\left.\mathrm{H}_{2}, J=17 \mathrm{~Hz}\right), 3.513\left(\mathrm{t}, 1 \mathrm{H}, \mathrm{H}_{3}, J=17 \mathrm{~Hz}\right), 2.758$ $\left(\mathrm{dd}, 1 \mathrm{H}, \mathrm{H}_{4}, J=4\right.$ and $\left.6 \mathrm{~Hz}\right), 6.417\left(\mathrm{~d}, 1 \mathrm{H}, \mathrm{H}_{5}, J=19\right.$ $\mathrm{Hz}), 6.617\left(\mathrm{~d}, 1 \mathrm{H}, \mathrm{H}_{6}, J=19 \mathrm{~Hz}\right), 1.826\left(\mathrm{dd}, 1 \mathrm{H}, \mathrm{H}_{7}\right.$, $J=8$ and $4 \mathrm{~Hz}), 1.676\left(\mathrm{dd}, 1 \mathrm{H}, \mathrm{H}_{7^{\prime}}, J=6\right.$ and $4 \mathrm{~Hz}$ ), 7.531-8.517 (m, 7H, Ar-H); ${ }^{13} \mathrm{C}$ NMR (100 MHz, $\left.\mathrm{CDCl}_{3}, 25^{\circ} \mathrm{C}, \mathrm{TMS}\right): \delta=198.64(\mathrm{CO}), 46.732\left(\mathrm{C}_{1}\right)$, $52.71\left(\mathrm{C}_{2}\right), 45.87\left(\mathrm{C}_{3}\right), 46.72\left(\mathrm{C}_{4}\right), 135.78\left(\mathrm{C}_{5},\right)$, $136.67\left(\mathrm{C}_{6}\right), 46.54\left(\mathrm{C}_{7}\right), 124.51-152.47$ (Ar-C).

(3-(3-Nitrophenyl)bicyclo[2.2.1]hept-5-en-2-yl)(3,4dichlorophenyl)methanone (Compound 15): IR ( $\mathrm{KBr}$, $\left.\mathrm{cm}^{-1}\right): v=3098,2875,1668,1554,1484,1056,981$, 882,$753 ;{ }^{1} \mathrm{H} \mathrm{NMR}\left(400 \mathrm{MHz}, \mathrm{CDCl}_{3}, 25{ }^{\circ} \mathrm{C}\right.$, TMS): $\delta=3.764\left(\mathrm{dd}, 1 \mathrm{H}, \mathrm{H}_{1}, J=4\right.$ and $\left.8 \mathrm{~Hz}\right), 3.623(\mathrm{t}, 1 \mathrm{H}$, $\left.\mathrm{H}_{2}, J=16 \mathrm{~Hz}\right), 3.519\left(\mathrm{t}, 1 \mathrm{H}, \mathrm{H}_{3}, J=16 \mathrm{~Hz}\right), 2.784$ $\left(\mathrm{dd}, 1 \mathrm{H}, \mathrm{H}_{4}, J=6\right.$ and $\left.4 \mathrm{~Hz}\right), 6.501\left(\mathrm{~d}, 1 \mathrm{H}, \mathrm{H}_{5}, J=15\right.$ $\mathrm{Hz}), 6.651\left(\mathrm{~d}, 1 \mathrm{H}, \mathrm{H}_{6}, J=15 \mathrm{~Hz}\right), 1.799\left(\mathrm{dd}, 1 \mathrm{H}, \mathrm{H}_{7}\right.$, $J=4$ and $6 \mathrm{~Hz}), 1.689$ (dd, $1 \mathrm{H}, \mathrm{H}_{7^{\prime}}, J=8$ and $4 \mathrm{~Hz}$ ), 7.634-8.513 (m, 7H, Ar-H); ${ }^{13} \mathrm{C}$ NMR (100 MHz, $\left.\mathrm{CDCl}_{3}, 25{ }^{\circ} \mathrm{C}, \mathrm{TMS}\right): \delta=199.87(\mathrm{CO}), 46.76\left(\mathrm{C}_{1}\right)$, $52.69\left(\mathrm{C}_{2}\right), 45.79\left(\mathrm{C}_{3}\right), 46.70\left(\mathrm{C}_{4}\right), 135.76\left(\mathrm{C}_{5},\right)$, $136.41\left(\mathrm{C}_{6}\right), 46.34\left(\mathrm{C}_{7}\right), 121.05-146.94$ (Ar-C).

(3-(4-Nitrophenyl)bicyclo[2.2.1]hept-5-en-2-yl)(3,4dichlorophenyl)methanone (Compound 16): IR ( $\mathrm{KBr}$, $\left.\mathrm{cm}^{-1}\right): v=3095,2884,1671,1562,1494,1073,959$, 852, 781; ${ }^{1} \mathrm{H} \mathrm{NMR} \mathrm{(400} \mathrm{MHz,} \mathrm{CDCl}_{3}, 25{ }^{\circ} \mathrm{C}$, TMS): $\delta=3.772\left(\mathrm{dd}, 1 \mathrm{H}, \mathrm{H}_{1}, J=8\right.$ and $\left.4 \mathrm{~Hz}\right), 3.697(\mathrm{t}, 1 \mathrm{H}$, $\left.\mathrm{H}_{2}, J=17 \mathrm{~Hz}\right), 3.521\left(\mathrm{t}, 1 \mathrm{H}, \mathrm{H}_{3}, J=17 \mathrm{~Hz}\right), 2.796$ $\left(\mathrm{dd}, 1 \mathrm{H}, \mathrm{H}_{4}, J=8\right.$ and $\left.4 \mathrm{~Hz}\right), 6.511\left(\mathrm{~d}, 1 \mathrm{H}, \mathrm{H}_{5}, J=16\right.$ $\mathrm{Hz}), 6.654$ (d, 1H, H6,$J=16 \mathrm{~Hz}), 1.835$ (dd, 1H, $\mathrm{H}_{7}$, $J=8$ and $4 \mathrm{~Hz}), 1.693\left(\mathrm{dd}, 1 \mathrm{H}, \mathrm{H}_{7^{\prime}}, J=6\right.$ and $8 \mathrm{~Hz}$ ), 7.562-8.551 (m, 7H, Ar-H); ${ }^{13} \mathrm{C}$ NMR (100 MHz, $\left.\mathrm{CDCl}_{3}, 25{ }^{\circ} \mathrm{C}, \mathrm{TMS}\right): \delta=199.94(\mathrm{CO}), 46.77\left(\mathrm{C}_{1}\right)$, $52.71\left(\mathrm{C}_{2}\right), 45.84\left(\mathrm{C}_{3}\right), 46.79\left(\mathrm{C}_{4}\right), 135.71\left(\mathrm{C}_{5}\right)$, $136.51\left(\mathrm{C}_{6}\right), 46.38\left(\mathrm{C}_{7}\right), 123.514-152.11(\mathrm{Ar}-\mathrm{C})$.

\subsection{Antimicrobial activity}

The prepared bicyclo[2.2.1]heptene-2-ylmethanones were subjected to evaluate the antimicrobial activities by measuring the zone of inhibition against their bacterial and fungal strains.
Two gram-positive pathogenic strains (Staphylococcus aureus, Enterococcus faecalis) and four gram-negative strains (Escherichia coli, Klebsiella pneumoniae, Pseudomonas aeruginosa and Proteus vulgaris) were applied for evaluation of antimicrobial activities. The Bauer-Kirby [38] disc diffusion technique was adopted at the concentration of $250 \mu \mathrm{g} / \mathrm{mL}$ of compounds with ampicillin and streptomycin as standards. The disc diffusion technique was used for the evaluation of antifungal activity of ketones against Candida albicans strain and the dilution method was adopted for Penicillium $s p$. and Aspergillus niger strains. The dilution concentration of the compounds are $50 \mu \mathrm{g} / \mathrm{mL}$ and Griseofulvin was employed as standard drug.

\subsubsection{Measurement of antibacterial sensitivity}

The Bauer-Kirby [38] disc diffusion technique was adopted for measurement of antibacterial sensitivity assay of all compounds. About $0.5 \mathrm{~mL}$ of bacterial test compounds were spread uniformly over solidified Mueller-Hinton agar. About $5 \mathrm{~mm}$ diameter of discs made from Whatmann No. 1 filter paper were placed on the medium with potential inhibitor solution. The plates were incubated for $24 \mathrm{~h}$ at $37{ }^{\circ} \mathrm{C}$ upside down for prevention of collection of water droplets over the medium. Then the plates were examined and the diameter values $(\mathrm{mm})$ of zone of inhibition were measured. The triplicate results were recorded.

\subsubsection{Measurement of antifungal sensitivity}

The Bauer-Kirby [38] disc diffusion technique was used for the evaluation of antifungal activity of synthesized methanones. The sterilized Potato Dextrose Agar medium was added to the Petri plates containing $1 \mathrm{~mL}$ of fungal strains. Uniform spread of the agar on the plates were performed by means of clock and anti-clockwise rotation of the discs. The test solution was prepared by dissolving $15 \mathrm{mg}$ of the methanones in $1 \mathrm{~mL}$ of DMSO solvent and it was applied on the discs. This medium was incubated to solidify for 24 or $72 \mathrm{~h}$ at 25 or $28^{\circ} \mathrm{C}$. Then these plates were examined for the evaluation of antifungal activity by means of measuring the diameter ( $\mathrm{mm}$ ) of zone of inhibition. Triplicate measurement results were recorded.

\subsection{Antioxidant activity}

The DPPH radical scavenging activity technique [39] was used for the measurement of antioxidant activity of all prepared methanones. About $20 \mathrm{~mL}$ of sodium acetate buffer solution was prepared by dissolving $1.64 \mathrm{~g}$ of sodium acetate in $15 \mathrm{~mL}$ of water and $150 \mu \mathrm{L}$ of acetic acid, and the final volume was adjusted to $20 \mathrm{~mL}$ of water. About $50 \mathrm{~mL}$ of $0.2 \mathrm{mmol}$ DPPH solution was prepared by dissolving $3.9 \mathrm{~g}$ of DPPH in $50 \mathrm{~mL}$ of ethanol. About $10 \mathrm{~mL}$ of $\alpha$ tocopherol solution was prepared by dissolving $1 \mathrm{mg}$ of $\alpha$-tocopherol in $10 \mathrm{~mL}$ of ethanol. About $1.0 \mathrm{~mL}$ 
of buffer solution was mixed with $0.5 \mathrm{~mL}$ of DPPH solution in the test tubes and arranged serially. The test solution and $\alpha$-tocopherol solution were added to the test tubes and kept aside for 30 minutes at room temperature. The absorbance was measured on an UV-Vis spectrophotometer (Shimadzu-1650) at 517 $\mathrm{nm}$. Mixture of sodium acetate buffer and ethanol was used as the reference. The plot was made with the quantity of the compound versus absorption and the $\mathrm{IC}_{50}$ values were determined. The antioxidant activity was expressed in terms of $\mathrm{IC}_{50}(\mu \mathrm{g} / \mathrm{mL}$, concentration required to inhibit DPPH radical formation by $50 \%$ ). $\alpha$-Tocopherol was taken as a positive control.

The radical scavenging activity was calculated as:
$D P P H$ radical scavenging activity $=$ $=\frac{\text { Control absorbance }- \text { Sample absorbance }}{\text { Control absorbance }} \times 100$

\section{Results and Discussion}

The synthesis of 3,4-dichlorophenyl bicyclo[2.2.1]heptene-2-yl-methanone derivatives by aqueous phase fly-ash catalyzed Diels-Alder reaction with cyclopentadiene as the diene and $E$-3,4dichlorophenyl chalcones as dienophiles was undertaken under solvent-free cooling conditions. During the reaction, the chemical species present in the fly-ash catalyzed the [4+2] cycloaddition reaction [25]. In this reaction the yield obtained was greater than $60 \%$. The determined physical constants and mass fragments are presented in Table 1.

Table 1. The analytical physical constants and mass fragments of (3-(3-substituted phenyl)bicyclo[2.2.1]hept-5en-2-yl)(3,4-dichlorophenyl)methanone derivatives

\begin{tabular}{|c|c|c|c|c|c|c|c|c|c|}
\hline \multirow[t]{2}{*}{ Entry } & \multirow[t]{2}{*}{$\mathbf{X}$} & \multirow[t]{2}{*}{ M.F. } & \multirow{2}{*}{$\begin{array}{c}\text { Yield } \\
(\%)\end{array}$} & \multirow[t]{2}{*}{ M.W. } & \multirow{2}{*}{$\begin{array}{l}\text { M.p. } \\
\left({ }^{\circ} \mathbf{C}\right)\end{array}$} & \multicolumn{3}{|c|}{ Micro analysis } & \multirow[t]{2}{*}{$\operatorname{Mass}(\mathbf{m} / \mathbf{z})$} \\
\hline & & & & & & $\begin{array}{c}\mathrm{C} \\
\text { (Cacld.) }\end{array}$ & $\begin{array}{c}\mathrm{H} \\
\text { (Cacld.) }\end{array}$ & $\begin{array}{c}\mathrm{N} \\
\text { (Cacld.) }\end{array}$ & \\
\hline 1 & $\mathrm{H}$ & $\mathrm{C}_{20} \mathrm{H}_{16} \mathrm{Cl}_{2} \mathrm{O}$ & 65 & 343 & $112-113$ & $\begin{array}{c}69.93 \\
(69.98)\end{array}$ & $\begin{array}{c}4.68 \\
(4.70)\end{array}$ & -- & $\begin{array}{l}343\left[\mathrm{M}^{+}\right], 345\left[\mathrm{M}^{2+}\right], 347\left[\mathrm{M}^{4+}\right] \\
308,265,230,173,170,145 \\
138,120,110,92,77,75,35 \\
28\end{array}$ \\
\hline 2 & $3-\mathrm{NH}_{2}$ & $\mathrm{C}_{20} \mathrm{H}_{17} \mathrm{Cl}_{2} \mathrm{NO}$ & 60 & 358 & $98-99$ & $\begin{array}{c}67.09 \\
(67.05)\end{array}$ & $\begin{array}{c}4.71 \\
(4.78)\end{array}$ & $\begin{array}{c}3.88 \\
(3.91)\end{array}$ & $\begin{array}{l}358\left[\mathrm{M}^{+}\right], 360\left[\mathrm{M}^{2+}\right], 362\left[\mathrm{M}^{4+}\right] \\
341,322,265,230,212,184, \\
173,145,138,120,110,92,77 \\
75,38,35,28,16\end{array}$ \\
\hline 3 & $3-\mathrm{Br}$ & $\mathrm{C}_{20} \mathrm{H}_{15} \mathrm{BrCl}_{2} \mathrm{O}$ & 60 & 422 & $107-108$ & $\begin{array}{c}56.93 \\
(56.90)\end{array}$ & $\begin{array}{c}3.49 \\
(3.56)\end{array}$ & --- & $\begin{array}{l}422\left[\mathrm{M}^{+}\right], 424\left[\mathrm{M}^{2+}\right], 426\left[\mathrm{M}^{4+}\right] \\
385,341,275,265,173,155 \\
145,120,110,92,79,35,28\end{array}$ \\
\hline 4 & $2-\mathrm{Cl}$ & $\mathrm{C}_{20} \mathrm{H}_{15} \mathrm{Cl}_{3} \mathrm{O}$ & 61 & 377 & $105-106$ & $\begin{array}{c}63.63 \\
(63.60)\end{array}$ & $\begin{array}{c}3.94 \\
(4.00)\end{array}$ & --- & $\begin{array}{l}377\left[\mathrm{M}^{+}\right], 379\left[\mathrm{M}^{2+}\right], 381\left[\mathrm{M}^{4+}\right] \\
341,306,265,173,145,120 \\
111,75,35\end{array}$ \\
\hline 5 & $3-\mathrm{Cl}$ & $\mathrm{C}_{20} \mathrm{H}_{15} \mathrm{Cl}_{3} \mathrm{O}$ & 61 & 377 & $114-115$ & $\begin{array}{c}63.58 \\
(63.60)\end{array}$ & $\begin{array}{c}3.97 \\
(4.00)\end{array}$ & --- & $\begin{array}{l}377\left[\mathrm{M}^{+}\right], 379\left[\mathrm{M}^{2+}\right], 381\left[\mathrm{M}^{4+}\right] \\
341,306,265,203,173,145 \\
120,111,103,75,35\end{array}$ \\
\hline 6 & $4-\mathrm{Cl}$ & $\mathrm{C}_{20} \mathrm{H}_{15} \mathrm{Cl}_{3} \mathrm{O}$ & 62 & 377 & $102-103$ & $\begin{array}{c}63.62 \\
(63.60)\end{array}$ & $\begin{array}{l}3.95 \\
(4.00)\end{array}$ & --- & $\begin{array}{l}377\left[\mathrm{M}^{+}\right], 379\left[\mathrm{M}^{2+}\right], 381\left[\mathrm{M}^{4+}\right] \\
341,306,265,203,173,145 \\
138,120,111,103,92,75,35\end{array}$ \\
\hline 7 & $\begin{array}{c}4- \\
\mathrm{N}\left(\mathrm{CH}_{3}\right)_{2}\end{array}$ & $\mathrm{C}_{22} \mathrm{H}_{21} \mathrm{Cl}_{2} \mathrm{NO}$ & 61 & 386 & $116-117$ & $\begin{array}{c}68.42 \\
(68.40)\end{array}$ & $\begin{array}{c}5.42 \\
(5.48)\end{array}$ & $\begin{array}{c}3.59 \\
(3.63)\end{array}$ & $\begin{array}{l}386\left[\mathrm{M}^{+}\right], 388\left[\mathrm{M}^{2+}\right], 390\left[\mathrm{M}^{4+}\right] \\
370,355,341,265,182,173 \\
145,138,120,110,92,90,76 \\
35,29,15\end{array}$ \\
\hline 8 & $4-\mathrm{F}$ & $\mathrm{C}_{20} \mathrm{H}_{15} \mathrm{Cl}_{2} \mathrm{FO}$ & 62 & 361 & $121-122$ & $\begin{array}{c}66.54 \\
(66.50)\end{array}$ & $\begin{array}{c}4.22 \\
(4.19)\end{array}$ & --- & $\begin{array}{l}361\left[\mathrm{M}^{+}\right], 363\left[\mathrm{M}^{2+}\right], 365\left[\mathrm{M}^{4+}\right] \\
341,265,187,173,145,120 \\
110,92,76,28,19\end{array}$ \\
\hline 9 & $2-\mathrm{OH}$ & $\mathrm{C}_{20} \mathrm{H}_{16} \mathrm{Cl}_{2} \mathrm{O}_{2}$ & 62 & 359 & $116-117$ & $\begin{array}{c}66.82 \\
(66.87)\end{array}$ & $\begin{array}{c}4.43 \\
(4.49)\end{array}$ & --- & $\begin{array}{l}359\left[\mathrm{M}^{+}\right], 361\left[\mathrm{M}^{2+}\right], 363\left[\mathrm{M}^{4+}\right] \\
341,323,271,265,230,185, \\
173,145,120,111,103,92,76, \\
35,28,17\end{array}$ \\
\hline 10 & $4-\mathrm{OH}$ & $\mathrm{C}_{20} \mathrm{H}_{16} \mathrm{Cl}_{2} \mathrm{O}_{2}$ & 62 & 359 & $123-124$ & $\begin{array}{l}66.88 \\
(66.87)\end{array}$ & $\begin{array}{c}4.40 \\
(4.49)\end{array}$ & --- & $\begin{array}{l}359\left[\mathrm{M}^{+}\right], 361\left[\mathrm{M}^{2+}\right], 363\left[\mathrm{M}^{4+}\right] \\
341,323,288,271,265,230 \\
216,213,195,185,173,145 \\
138,120,110,103,92,76,35 \\
28,17\end{array}$ \\
\hline 11 & $3-\mathrm{OCH}_{3}$ & $\mathrm{C}_{21} \mathrm{H}_{18} \mathrm{Cl}_{2} \mathrm{O}_{2}$ & 67 & 373 & $113-114$ & $\begin{array}{c}67.59 \\
(67.57)\end{array}$ & $\begin{array}{c}4.82 \\
(4.86)\end{array}$ & -- & $\begin{array}{l}373\left[\mathrm{M}^{+}\right], 375\left[\mathrm{M}^{2+}\right], 377\left[\mathrm{M}^{4+}\right] \\
357,341,265,227,173,145, \\
120,110,107,91,76,35,28,15\end{array}$ \\
\hline 12 & $4-\mathrm{OCH}_{3}$ & $\mathrm{C}_{21} \mathrm{H}_{18} \mathrm{Cl}_{2} \mathrm{O}_{2}$ & 67 & 373 & $118-120$ & $\begin{array}{c}67.55 \\
(67.57)\end{array}$ & $\begin{array}{c}4.79 \\
(4.86)\end{array}$ & --- & $\begin{array}{l}373\left[\mathrm{M}^{+}\right], 375\left[\mathrm{M}^{2+}\right], 377\left[\mathrm{M}^{4+}\right] \\
357,341,265,227,199,192, \\
173,145,120,110,107,91,76, \\
35,28,15\end{array}$ \\
\hline 13 & 4- $\mathrm{CH}_{3}$ & $\mathrm{C}_{21} \mathrm{H}_{18} \mathrm{Cl}_{2} \mathrm{O}$ & 65 & 357 & $122-123$ & $\begin{array}{c}70.62 \\
(70.60)\end{array}$ & $\begin{array}{l}5.02 \\
(5.08)\end{array}$ & --- & $\begin{array}{l}357\left[\mathrm{M}^{+}\right], 359\left[\mathrm{M}^{2+}\right], 361\left[\mathrm{M}^{4+}\right] \\
341,321,286,265,211,196\end{array}$ \\
\hline
\end{tabular}




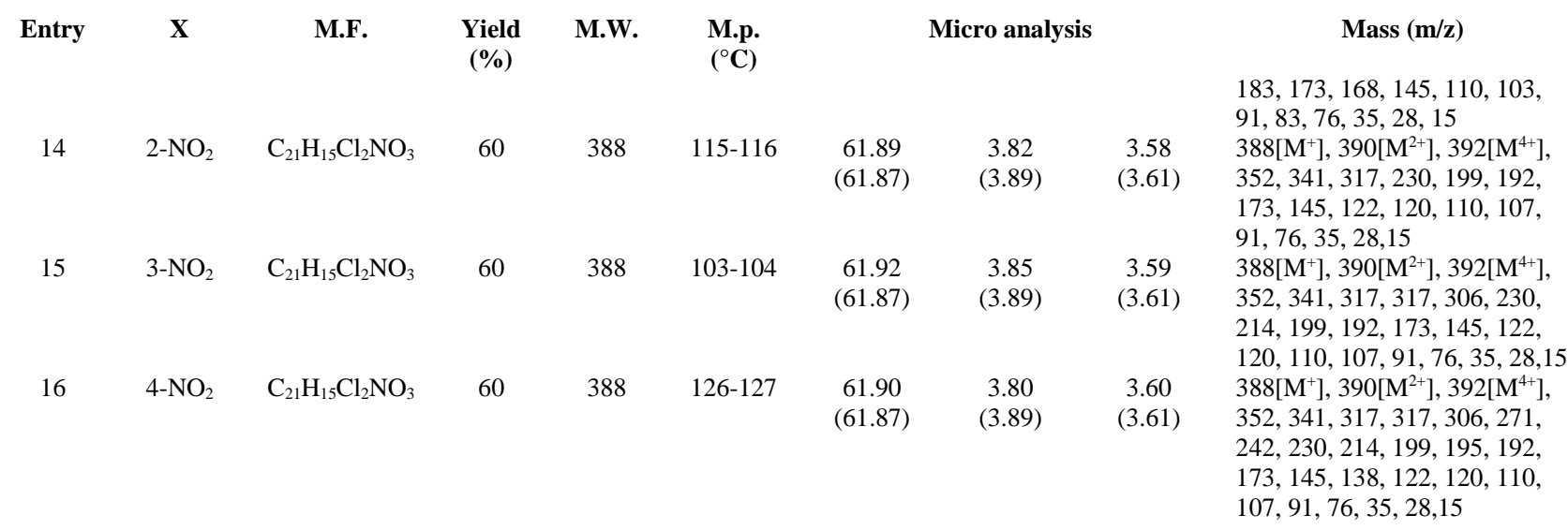

Table 2. Antibacterial ${ }^{\mathrm{a}}$, antifungal ${ }^{\mathrm{b}}$ and antioxidant ${ }^{\mathrm{c}}$ activities (3-(3-substituted phenyl)bicyclo[2.2.1]hept-5-en2-yl)(3,4-dichlorophenyl)methanones.

\begin{tabular}{|c|c|c|c|c|c|c|c|c|c|c|}
\hline \multirow{3}{*}{ 己 } & \multirow{2}{*}{\multicolumn{6}{|c|}{ Antibacterial activity }} & \multicolumn{3}{|c|}{ Antifungal activity } & \multirow{3}{*}{$\begin{array}{c}\text { Antioxidant } \\
\text { activity } \\
\text { (DPPH } \\
\text { radical } \\
\text { scavenging) }\end{array}$} \\
\hline & & & & & & & \multirow{2}{*}{ 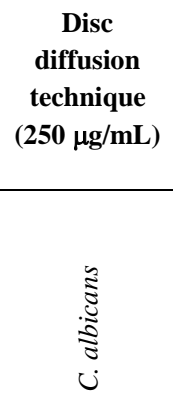 } & \multicolumn{2}{|c|}{$\begin{array}{l}\text { Drug dilution } \\
\text { method } \\
(250 \mu \mathrm{g} / \mathrm{mL})\end{array}$} & \\
\hline & $\begin{array}{l}\overrightarrow{0} \\
0 \\
0\end{array}$ & $\begin{array}{c}\tilde{y} \\
\stackrel{\Xi}{\Xi} \\
\dot{s}\end{array}$ & 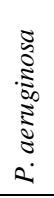 & 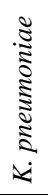 & $\begin{array}{l}0 \\
0 \\
0 \\
0 \\
0 \\
0 \\
0\end{array}$ & 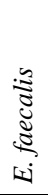 & & 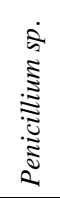 & $\begin{array}{l}\bar{\Xi} \\
\stackrel{0}{\Xi} \\
\dot{+}\end{array}$ & \\
\hline 1 & + & + & + & + & \pm & + & \pm & + & + & $18.08 \pm 1.08$ \\
\hline 2 & + & \pm & + & + & + & \pm & ++ & + & ++ & $23.81 \pm 1.94$ \\
\hline 3 & ++ & ++ & ++ & ++ & ++ & + & + & + & + & $19.58 \pm 1.09$ \\
\hline 4 & ++ & ++ & ++ & ++ & + & ++ & \pm & \pm & + & $22.95 \pm 1.54$ \\
\hline 5 & ++ & ++ & ++ & ++ & ++ & ++ & \pm & \pm & + & $21.45 \pm 1.64$ \\
\hline 6 & ++ & ++ & ++ & ++ & ++ & ++ & \pm & \pm & \pm & $17.95 \pm 1.24$ \\
\hline 7 & + & - & \pm & + & + & \pm & ++ & ++ & ++ & $27.01 \pm 1.65$ \\
\hline 8 & ++ & ++ & ++ & ++ & ++ & ++ & \pm & + & + & $25.34 \pm 1.72$ \\
\hline 9 & + & ++ & + & \pm & \pm & \pm & + & ++ & + & $36.04 \pm 1.82$ \\
\hline 10 & \pm & + & + & ++ & \pm & + & + & \pm & ++ & $37.99 \pm 1.01$ \\
\hline 11 & ++ & + & \pm & + & ++ & \pm & + & + & ++ & $35.12 \pm 1.11$ \\
\hline 12 & ++ & ++ & ++ & ++ & ++ & ++ & + & ++ & \pm & $35.56 \pm 0.86$ \\
\hline 13 & ++ & + & \pm & \pm & + & + & + & \pm & \pm & $29.45 \pm 1.50$ \\
\hline 14 & \pm & \pm & \pm & \pm & + & \pm & ++ & ++ & ++ & $22.34 \pm 1.45$ \\
\hline 15 & + & \pm & \pm & + & \pm & \pm & ++ & ++ & ++ & $20.37 \pm 1.28$ \\
\hline 16 & \pm & \pm & \pm & \pm & \pm & + & ++ & ++ & ++ & $20.05 \pm 1.09$ \\
\hline
\end{tabular}

${ }^{a}$ Disc size: $6.35 \mathrm{~mm}$; duration: $24-45$ h; standard: ampicillin (30-33 mm) and streptomycin (20-25 mm); control: methanol; -: no activity; \pm : active $(8-12 \mathrm{~mm}) ;+$ : moderately active $(13-19 \mathrm{~mm}) ;++:$ active $(20-24 \mathrm{~mm})$.

${ }^{b}$ Standard: griseofulvin and gentamycin; duration: 72 h; control: methanol; medium: Potato dextrose agar; $++:$ no fungal colony; +: one fungal colony; \pm : two-three fungal colonies; -: Multiple fungal colonies.

'Standard: $\alpha$-Tocopherol (39.14 \pm 1.57$)$

The catalyst was reusable up to $5^{\text {th }}$ run [25]. The chalcone containing electron-donating substituents $\left(\mathrm{OCH}_{3}\right)$ gave higher yield than electron-withdrawing (halogen and nitro) substituents. The effect of solvents on the percentage of product of this reaction for compound $\mathbf{1}$ was studied with the same quantity of reactants with methanol, dichloromethane, dioxane and tetrahydrofuran. The highest yield was obtained in ethanol with fly-ash in water medium $(65 \%)$. The infrared and NMR data of compounds are summarized in experimental section. 


\subsection{Antibacterial sensitivity assay}

The disc-diffusion technique was followed using the Bauer-Kirby [38] method, at a concentration of $250 \mu \mathrm{g} / \mathrm{mL}$, with ampicillin and streptomycin used as the standard drugs. All methanones show antibacterial activities against their bacterial strains. The measured antibacterial activities of all methanones are presented in Table 2. Compounds 3-6, 8, 11-13, showed the maximum zone of inhibition against Escherichia coli, at 20-24 mm, compared to other methanones such as $\mathbf{2 , 7 , 9 , 1 2}$ and $\mathbf{1 5}$. These latter compounds are moderately active, with 13-19 mm zones of inhibition. Ketones 10, 14 and 16 were active with an $8-12 \mathrm{~mm}$ of zone of inhibition. The ketones 1, 3-6, 9 and 12 were found to be effective against $S$. aureus strain with $20-24 \mathrm{~mm}$ of zones of inhibition. Compounds 7, 10, 11 and 13 are moderately active with $13-19 \mathrm{~mm}$ of zones of inhibition. The methanones 2 and 14-16 were active with an $8-12 \mathrm{~mm}$ zone of inhibition. The methanone derivatives 3-6, 8 and $\mathbf{1 2}$ were shown to be more active against Pseudomonas, with greater than a 20 $\mathrm{mm}$ zone of inhibition, while the other derivatives showed zones of inhibition between 12-19 $\mathrm{mm}$. Compounds 1, 2, 9 and 10 were moderately active against the Pseudomonas aeruginosa strain at 13-19 $\mathrm{mm}$ of zone of inhibition. Methanones 7, 11 and 1316 were active at $8-12 \mathrm{~mm}$ of zone of inhibition. Ketones 3-6, 8, 12 and 10 were more effective against the Klebsiella pneumoniae strain with 20-24 mm zones of inhibition, while ketone 1, 2, 7, 11 and 15 showed moderate activity with a $13-19 \mathrm{~mm}$ zone of inhibition. Compounds 9, 13, 14 and 16 were active with an 8-12 $\mathrm{mm}$ zone of inhibition. The methanones $3,5,6,8,11$ and 12 were active when they were screened with Phaseolus vulgaris with 20-24 mm zones of inhibition and compounds 2, 4, 7, 13 and 14 were moderately active with $13-19 \mathrm{~mm}$ zones of inhibition. The ketones 4-6, 8, 10 and 12 showed greater activity against Enterococcus faecalis, with 20-24 mm zones of inhibition. Compounds 1-3, 13 and 16 were moderately active with $13-19 \mathrm{~mm}$ zones of inhibition. The methanones derivatives $\mathbf{2}$, $7,9,11,14$ and 15 were active with $8-12 \mathrm{~mm}$ zones of inhibition.

\subsection{Antifungal sensitivity assay}

The observed antifungal activities of all prepared methanones are presented in Table 2. The study of antifungal activities of all methanones against Candida albicans showed that compounds 2, 3, 7 and 14-16 are most effective, with $20 \mathrm{~mm}$ zones of inhibition at $250 \mu \mathrm{g} / \mathrm{mL}$ per disc, while methanones 4, 9 and 11-13 are moderately active with $13-19 \mathrm{~mm}$ zones of inhibition and compounds 1, 5, 6 and 8 were active with an $8-12 \mathrm{~mm}$ zone of inhibition. Compounds 7, 9, 12, and 14-16 are more effective against Penicillium species relative to compounds 1, 2, 3 and 11. The methanones 4-6, 8, 10 and 13 were active against the Penicillium sp. fungal strain. The zone of inhibition of ketones 2, 7, 10, 11 and 14-16 were most effective against Aspergillus niger relative to compounds 1, 3-5, 8 and 9 . The ketones 6, 12 and 13 showed little effectiveness with a fungal strain. The presence of a halo, diethyl, dimethyl, fluoro, methoxy and nitro substituents appears to be responsible for the antimicrobial activities of methanones.

\subsection{Antioxidant activity}

The antioxidant activities of (3,4dichlorophenyl)-3-(substituted phenyl)bicyclo[2.2.1] hept-5-ene-2-yl) methanone derivatives were measured using the DPPH radical scavenging method [39]. The observed antioxidant activities of methanones are presented in Table 2. From the Table 2 , the hydroxy- and methoxy-substituted methanones (compounds $\mathbf{1 0}$ and 9) showed significant antioxidant activity. The other ketones including the parent compound showed lesser antioxidant activity.

\section{Conclusions}

A series of (3,4-dichlorophenyl)-3-(substituted phenyl)bicyclo[2.2.1]hept-5-ene-2-yl) methanone derivatives have been synthesized by aqueous-phase fly-ash catalyzed Diels-Alder [4+2] cycloaddition of cyclopentadiene and aryl (E)-3,4dichlorophenylchalcones. The yields of the methanones were greater than $60 \%$. The antimicrobial activities of the methanones have been evaluated using Bauer-Kirby methods. All compounds are active in antibacterial and antifungal activity against their microbial strains. The methanones 1, 3-6 and 8-12 were most active against E. coli, S. aureus, $P$. aeruginosa, $K$. pneumoniae, $P$. vulgaris and $E$. faecalis bacterial strains with 20-24 $\mathrm{mm}$ of zones of inhibition. Methanone derivatives 2, 7, 9 and 15 were moderately active against E. coli, $S$. aureus, $P$. aeruginosa, $K$. pneumoniae, $P$. vulgaris and $E$. faecalis bacterial strains with $13-19 \mathrm{~mm}$ of zones of inhibition. The ketones 10 and 14-16 were more active against $E$. coli, $S$. aureus, $P$. aeruginosa, $K$. pneumoniae, $P$. vulgaris and $E$. faecalis bacterial strains with 8-12 $\mathrm{mm}$ of zones of inhibition. Compounds 2, 7 and 14-16 were most active against $C$. albicans and Penicillium sp. and A. niger fungal strains within $20 \mathrm{~mm}$ of zone of inhibitions. Methanones 1, 3,9 and 11-13 were active $C$. albicans and Penicillium sp. fungal strains within $13 \mathrm{~mm}$ of zone of inhibitions. The ketones 1, 4-6, 8, 10 and 12 developed a zone of inhibitions within $8 \mathrm{~mm}$. The all halo substituted compounds show antimicrobial activities. The antioxidant activities of the methanones were measured by a DPPH radical scavenging method; the compounds containing hydroxy and methoxy substituents showed antioxidant activity. 


\section{Acknowledgment}

The author gratefully acknowledges the University Grants Commission, New Delhi, India, for financial support Grant No. F.30-23/2011(SA-II), through the UGC-PDF Research Award.

\section{References}

[1] A.M. Amer, I.A.G. Attia, M. El-Mobayad, S. Askar, Polish J. Chem. 74, 681 (2000).

[2] V.E.Torres, X. Wang, Q. Qian, S. Somlo, P.C. Harris, V.H. Gattone, Nat. Med. 10, 363 (2004).

[3] A. Lagumdzija, Journal Club No. 576 (2012).

[4] C.M. Jamkhandi, J.I. Disouza, Int. J. Pharm. Pharm. Sci. 3, 225 (2013).

[5] J. Liu, F. Jiang, W. Zhang, J. Liu, W. Lu, W. Liu, L. Fu, Eur. J. Med. Chem. 54, 879 (2012).

[6] M. Das, P.S. Ghosh, K. Manna, Int. J. Med. Chem., article ID 9706753 (2016). http://dx.doi.org/10.1155/2016/9706753

[7] L. Mallesha, K.N. Mohana, Can. Chem. Trans. 2, 343 (2014).

[8] F.A. Bassyouni, H.A. Tawfik, A.R. Hamed, M.M. Soltan, M. El-Hefnawi, A.A. El-Rashedy, M.E. Moharam, M.A. Rehim, Egyptian Pharm. J. 11, 80 (2012).

[9] M.F. El-Behairy, T.E. Mazeed, A.A. ElAzzouny, M.N. Aboul-Enein, Saudi Pharm. J. 23, 202 (2015).

[10] P.B. Mohite, V.H. Bhaskar, Int. J. Pharm. Tech. Res. 3, 1557 (2001).

[11] M. Koca, M. Ahmedzade, A. Cukurovali, C. Kazaz, Molecules 10, 747 (2005).

[12] N.R. Mohan, S. Sreenivasa, K.E. Manojkumar, T.M.C. Rao, B.S. Thippeswamy, P.A. Suchetan, J. Braz. Chem. Soc. 25, 1012 (2014).

[13] R. Deshpande, M. Bhagavan Raju, S. Parameshwar, S.M. Shanth Kumar, S. Appalaraju, S. Yelagatti, Am. J. Chem. 2, 115 (2012).

[14] V. Srinivasa Murthy, B.K. Manuprasad, S. Shashikanth, J. Appl. Pharm. Sci. 2, 172 (2012).

[15] D.B. Yogesh, D.B. Shenoy, S.K. Agarwal, T. Menaka, G.R. Srinivasa, G. Nagaraja, U.S. Sunil Kumar, J. Chem. Pharm. Res. 5, 184 (2013).

[16] C.L. Chin, A.E. Tovcimak, V.P. Hradil, T.R. Seifert, P.R. Hollingsworth, P. Chandran, C.Z. Zhu, D. Gauvin, M. Pai, J. Wetter, G.C. Hsieh, P. Honore, J.M. Frost, M.J. Dart, M.D. Meyer, B.B. Yao, B.F. Cox, G.B. Fox, British. J. Pharmcol. 153, 367 (2008).

[17] A. Nencini, C. Castaldo, T.A. Comery, J. Dunlop, E. Genesio, C. Ghiron, S. Haydar, L. Maccari, I. Micco, E. Turlizzi, R. Zanaletti, J. Zhang, Eur. J. Med. Chem. 78, 401 (2014).
[18] H. Mohamed Ibrahim, Y. Nabil Mahmoud, N. Hany Fathy, E. Mohey, A. Mahmoud Soliman, Acta Pharm. 58, 15 (2008).

[19] L. Kumar, B. Shashi, J. Kamal, Int. J. Res. Pharm. Sci. 2, 23 (2002).

[20] L. Srikanth, V. Varun Raj, N. Raghunandan, L.Venkateshwaralu, Der Pharma Chemica 3, 172 (2011).

[21] R. Mahesh, B. Kumar, A. Jindal, S. Bhatt, T. Devadass, D.K. Pande, Indian J. Pharmacol. 44, 560 (2012).

[22] F.L. Zheng, S.R. Ban, X.E. Feng, C.X. Zhao, W. Lin, Q.S. Li, Molecules 16, 4897 (2011).

[23] P. Subbarj, A. Ramu, N. Raman, J. Dharmaraja, Int. J. Emer. Sci. Eng. 1, 79 (2013).

[24] J. Greeson, L. Lecanu, V. Papadopoulos, Patent No. WO 2005108378 A2, 2005, PCT/US2005/012028

[25] G. Thirunarayanan, Q-Science Connect (2014). DOI: http://dx.doi.org/ 10.5339/ connect.2014.18.

[26] E.B. Mubofu, J.B.F.N. Engberts, J. Phys. Org. Chem. 17, 180 (2004).

[27] R. Breslow, U. Marita, D.C. Rideout, Tetrahedron Lett. 14, 1901 (1983).

[28] R. Breslow, U. Marita, Tetrahedron Lett. 25, 1239 (1984).

[29] D. C. Rideout, R. Breslow, J. Am. Chem. Soc. 102, 7816 (1980).

[30] S. Otto, J.B.F.N. Engberts, Tetrahedron Lett. 36, 2645 (1995).

[31] R.P. Megens, G. Roefes, Chem. Eur. J. 17, 8514 (2011).

[32] Q. Jin, L. Zhang, H. Cao, T. Wang, X. Zhu, J. Jiang, M. Liu, Langmuir 27, 13847 (2011).

[33] A.J. Boersma, B.L. Feringa, G. Roelfes, Org. Lett. 9, 3647 (2007).

[34] G. Roelfes, A.J. Boersma, B.L. Feringa, Chem. Commun. 6, 635 (2006).

[35] C.H. Kuo, C.M. Niemeyer, L. Fruk, Croat. Chem. Acta. 84, 269 (2011).

[36] N.S. Oltra, G. Roelfes, Chem. Commun. 45, 6039 (2008).

[37] S. Otto, J.B.F.N. Engberts, J.C.T. Kwak, J. Am. Chem. Soc. 120, 9517 (1998).

[38] A.W. Bauer, W.M.M. Kirby, J.C. Sherris, M. Truck, Am. J. Clin. Pathol. 45, 493 (1966).

[39] M. Subramanian, G. Vanangamudi, G. Thirunarayanan, Spectrochim. Acta, 110A, 116 (2013).

[40] G. Thirunarayanan, P. Mayavel, K. Thirumurthy, Spectrochim. Acta, 91A, 18 (2012).

Received: 24 January 2016

Received in revised form: 5 March 2016

Accepted: 7 March 2016 